\title{
Sustained effort required to remove pop and sweets from sport
}

as has been previously applied to alcohol, tobacco, and gambling. While there are moves to ban junk food advertising in primetime, sports sponsorship appears to offer a get-out clause.

Dentists have previously warned that even diet versions of fizzy drinks are more acidic than lemon juice or vinegar, and are helping to fuel an epidemic of dental erosion.

This summer's Tokyo games will be the first Olympics in over 40 years not sponsored by burger giant McDonalds.

\section{Junk food advertising}

Later in June, the Department of Health and Social Care announced that following a public consultation, regulations will come into force at the end of 2022 to introduce a $9 \mathrm{pm}$ watershed for advertisements of foods high in fat, salt and sugar (HFSS). ${ }^{1}$

The new rules apply to TV and UK on-demand programmes, as well as restrictions on paid-for advertising of HFSS foods online, as part of the government's ongoing commitment to tackle unhealthy eating habits at source.

The Faculty of Dental Surgery at the Royal College of Surgeons of England (FDS) welcomed the announcement. Matthew Garrett, Dean, said: 'We have seen much lower children's dental attendance over the last 12 months due to COVID and this is another risk factor to poor oral health. Therefore, it is more important than ever to limit the amount of sugar that children eat and drink.
'Introducing a $9 \mathrm{pm}$ watershed for these advertisements on TV, and restricting such content online, are measures that the FDS and a range of other organisations across the health sector have been calling for over a number of years. Thus, today's announcement is a significant step forward. We now urge the government to implement these proposals in full in the forthcoming Health and Care Bill.'

The Oral Health Foundation also welcomed the new restrictions and acknowledged that it is a step in the right direction, but worries that there is still a lot more work to do.

CEO Dr Nigel Carter said: ‘The proposed ban on junk food television advertising is a great first step, however will still be allowed through audio media, such as podcasts and radio, and there will be no new restrictions for the out-of-home sector, which includes billboards, poster sites, on buses, and in locations such as railway stations and airports.

'With many young children now also consuming more and more media online through things like Amazon Prime and YouTube, they may still be able to see junk food advertising through these channels.

'Extending these restrictions to cover all media types, especially streaming platforms, is the next natural progression.'

\section{Reference}

1. Department of Health and Social Care. New advertising rules to help tackle childhood obesity. 24 June 2021. Available at: https://www.gov.uk/government/news/ new-advertising-rules-to-help-tackle-childhood-obesity (accessed 25 June 2021). on 25 June. They will serve most of their terms as Council Members of the College of General Dentistry (CGDent) following the transfer of the Faculty into CGDent.

\section{OBE Overseas}

In the Queen's Birthday Honours 2021 Overseas and International List, Dr Simon Stretton-Downes was awarded OBE for services to dentistry in Africa, particularly in Liberia. Dr StrettonDownes is lead dental surgeon at Trinity Dental Clinic, Eternal Love Winning Africa (ELWA) Hospital, Liberia. 